\title{
BMJ Open Association between physician characteristics and payments from industry in 2015-2017: observational study
}

Kosuke Inoue, $^{1}$ Daniel M Blumenthal, ${ }^{2,3,4}$ David Elashoff, ${ }^{5,6,7}$ Yusuke Tsugawa ${ }^{\circledR, 8}$

To cite: Inoue K,

Blumenthal DM, Elashoff D, et al. Association between physician characteristics and payments from industry in 2015-2017: observational study. BMJ Open 2019;9:e031010. doi:10.1136/ bmjopen-2019-031010

- Prepublication history and additional material for this paper are available online. To view these files, please visit the journal online (http://dx.doi. org/10.1136/bmjopen-2019031010).

Received 10 April 2019

Revised 26 July 2019

Accepted 23 August 2019
Check for updates

(C) Author(s) (or their employer(s)) 2019. Re-use permitted under CC BY-NC. No commercial re-use. See rights and permissions. Published by BMJ.

For numbered affiliations see end of article.

Correspondence to

Dr Kosuke Inoue;

koinoue@ucla.edu

\section{ABSTRACT}

Objective To investigate the association between physician characteristics and the value of industry payments.

Design Observational study.

Setting and participants Using the 2015-2017 Open Payments reports of industry payments linked to the Physician Compare database, we examined the association between physician characteristics (physician sex, years in practice, medical school attended and specialty) and the industry payment value, adjusting for other physician characteristic and institution fixed effects (effectively comparing physicians practicing at the same institution). Main outcome measures Our primary outcome was the value of total industry payments to physicians including (1) general payments (all forms of payments other than those classified for research purpose, eg, consulting fees, food, beverage), (2) research payments (payments for research endeavours under a written contract or protocol) and (3) ownership interests (eg, stock or stock options, bonds). We also investigated each category of payment separately.

Results of 544264 physicians treating Medicare beneficiaries, a total of $\$ 5.8$ billion in industry payments were made to 365801 physicians during 2015-2017. The top $5 \%$ of physicians, by cumulative payments, accounted for $91 \%$ of industry payments. Within the same institution, male physicians, physicians with 21-30 years in practice and physicians who attended top 50 US medical schools (based on the research ranking) received higher industry payments. Across specialties, orthopaedic surgeons, neurosurgeons and endocrinologists received the highest payments. When we investigated individual types of payment, we found that orthopaedic surgeons received the highest general payments; haematologists/ oncologists were the most likely to receive research payments and surgeons were the most likely to receive ownership interests compared with other types of physicians.

Conclusions Industry payments to physicians were highly concentrated among a small number of physicians. Male sex, longer length of time in clinical practice, graduated from a top-ranked US medical school and practicing certain specialties, were independently associated with higher industry payments.

\section{Strength and limitations of this study}

- The latest and most comprehensive data of the financial relationships between industry and physicians were used by linking a nationally representative Open Payments database with the national database of physicians treating Medicare beneficiaries.

- We examined both the total amount of industry payments to physicians and each category of payment (ie, general payments, research payments and ownership interests), which have not been investigated in prior studies.

- Limitations are the physician database was restricted to physicians treating Medicare beneficiaries and the temporal relationship could not be assessed with the cross-sectional design.

\section{INTRODUCTION}

A significant body of research suggests that physicians' financial relationships with industry may influence medical research, education and patient care, including clinical decisions about which medicines to prescribe. ${ }^{1-11}$ Concerns about the consequences of physicians' financial conflict of interest and inconsistent disclosure of these conflicts, led to the creation of the Open Payments programme under the Physician Payment Sunshine Act (known as the 'Sunshine Act', enacted as part of the Affordable Care Act). The Sunshine Act requires medical product manufacturers and group purchasing organisations (GPOs) to publicly report data on all payments and ownership interests made to licensed physicians (except residents) and teaching hospitals since $2013 .{ }^{12}$ The Open Payments database is the most exhaustive and reliable source of data on industry payments to physicians to date. ${ }^{13-15}$

The characteristics of physicians who receive large payments from industry remain incompletely characterised. Several studies have reported that industry payments may 
vary substantially based on physicians' sex, ${ }^{14-17}$ clinical experience ${ }^{1618}$ and specialty. ${ }^{10151920}$ In addition, a recent study that reported association of physicians' alma mater, medical school ranking and their prescription patterns (for opioids), sheds light on the importance of medical education on physician behaviour, which could potentially impact how industry approach physicians. ${ }^{21}$ However, these studies did not adjust for a comprehensive set of physician characteristics, due to lack of the data, and, therefore, it is possible that their findings may be biased if they left out an important physician-level confounder. In other words, it remains unclear whether four important characteristics of physicians-physicians' sex, years in practice, finely categorised specialties and medical school attended-are independently associated with the value of industry payments they receive. Moreover, most prior work on this topic has focused exclusively on non-research payments, despite the fact that some pharmaceutical companies have been using research payments aggressively to influence physicians' prescription of opioid products, ${ }^{22-24}$ underscoring the importance of evaluating all forms of payments. Therefore, a better characterisation of physician-level factors associated with higher industry payments-both non-research and research payments from industry-would help to advance our understanding of the financial relationships between industry and practicing US physicians and their potential impact on prescribing patterns and care quality.

In this study, we used a nationally representative database of industry payments to physicians linked with a comprehensive database of physicians treating Medicare beneficiaries, to investigate associations between a broad set of physician characteristics including-sex, years in practice, medical school and clinical specialty-and the value of payments (total amount of industry payments, as well as non-research and research payments separately) received from industry.

\section{METHODS}

\section{Data sources}

We linked three databases: (1) the 2015-2017 Centers for Medicare and Medicaid Services (CMS) Open Payments database (accessed September 2018), (2) the CMS National Plan \& Provider Enumeration System (NPPES) database (accessed September 2018) and (3) the CMS Physician Compare database (accessed January 2019).$^{25}$ Data from the 2015-2017 Open Payments programme included data on all general payments, research payments and ownership interests that industry paid physicians in each year. Biomedical companies report payment information to the CMS and physicians are asked to review the information before publication and dispute submitted reports if the information is incorrect. The CMS reported more than $98.8 \%$ of submitted payment records were validated in 2014 using the automated algorithm, which rejects payment records if they report inconsistent physician identifiers and provides real-time feedback to industries. ${ }^{13}$ The Physician Compare database developed by the CMS contains general information on all eligible healthcare providers (physicians, nurses and so on, with at least one practice location address/specialty code in the Medicare Provider Enrollment, Chain, and Ownership System who submitted at least one annual Medicare claim) including the National Provider Identification (NPI) number registry, sex, years in practice, specialty, medical school attended and practice location. ${ }^{25}$

We first linked physician information from the Open Payments database with the 2017 NPPES database using physicians' full name and the zip code for their primary practice location, an approach employed in previous studies. ${ }^{101519}$ Next, we used each physician's NPI number to linked the new merged dataset containing Open Payments and NPPES data with the Physician Compare database. Given that physicians who do not treat Medicare beneficiaries were not included in the Physician Compare database, our final sample size became 544264 (see online supplementary figure 1 for more details).

\section{Physician characteristics}

We examined four characteristics of physicians: sex, years in practice, medical school attended and specialty. We defined years in practice as years since graduation from medical school and categorised physicians into four groups: $\leq 10,11-20,21-30$ and $>30$ years since graduation. As in prior studies, we used the 2017 U.S. News $\mathcal{E}^{\circ}$ World Report research ranking, ${ }^{26} 27$ to categorise medical schools into three groups: (1) top 20 US medical schools for research, (2) US medical schools ranked between 21 and 50 and (3) other medical schools (since only top 50 medical schools are ranked, we classified all unranked and foreign medical schools into this 'other' category). In table 1, we classified physician specialty into 33 distinct categories. We created indicator variables for practice location using the physical address of individual physicians in the NPPES database.

\section{Payment data}

Physician payments were classified into three categories: general payments, research payments and ownership interests. General payments included all forms of payments other than those classified for research purposes, including food and beverage, travel and lodging, speaker compensation, honoraria, consulting fees, gifts and education materials (eg, textbooks and reprints of journal articles). Research payments are financial payments related to research under a written contract or protocol (including payments for medical research writing or publication). Ownership interests include stocks or stock options (not publicly traded), partnership shares, bonds and ownership stake in a limited liability company.

Our primary outcome was the total annual value of reported payments-the sum of general payments, research payments and ownership interests-to physicians (calculated by dividing the total value of payments from 
Table 1 Physician characteristics and type of industry payments

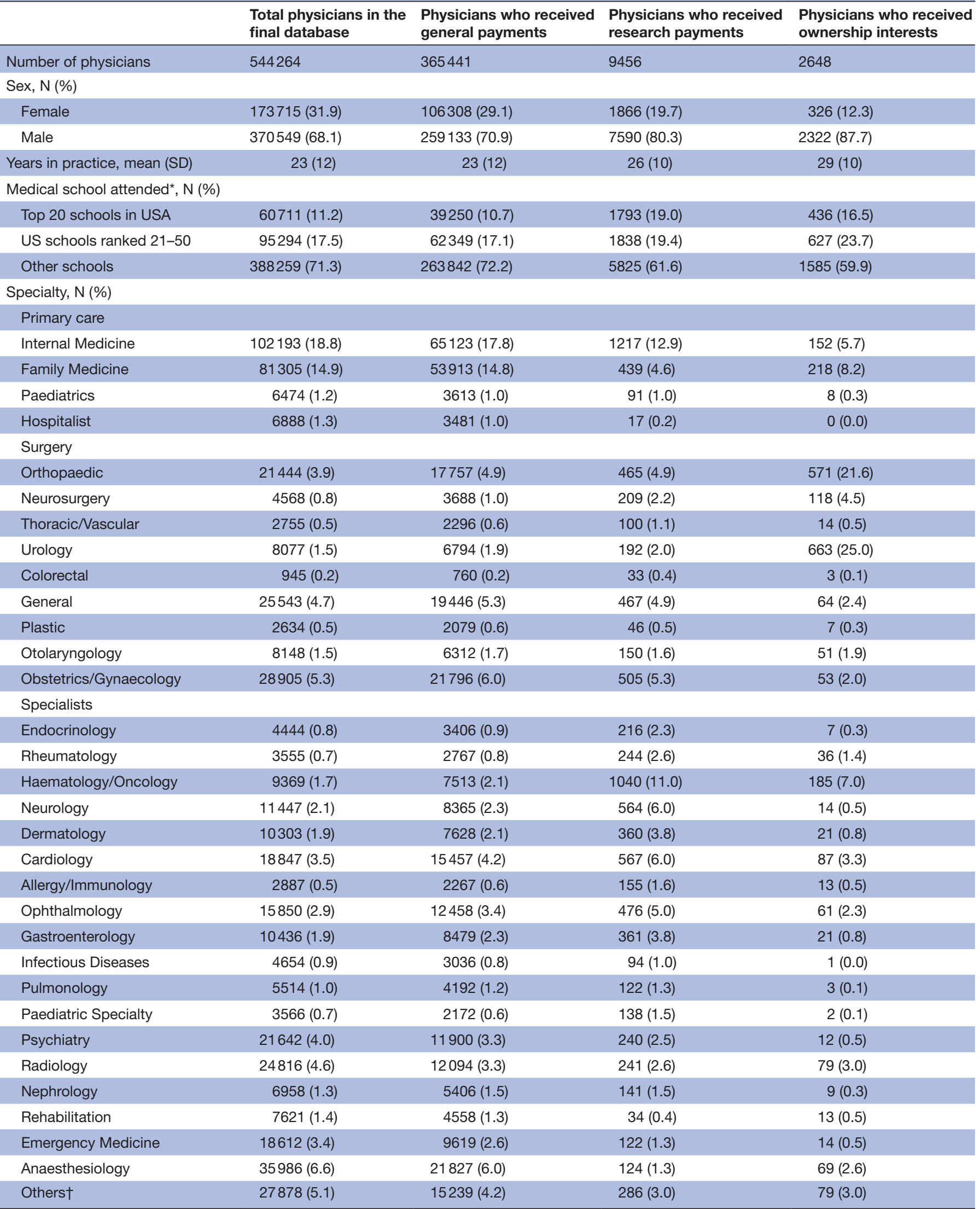

*Defined based on the U.S. News \& World Report ranking (research ranking) in 2017.

†Others include surgical oncology, oral surgery, radio oncology, pathology, nuclear medicine and so on. 
industry in 2015-2017 by three). Secondary outcomes were the annual value of each type of payment (ie, general payments, research payments and ownership interests) in 2015-2017. We focused on the total value of industry payments (we also examined the number of industry payments in a sensitivity analysis), because payments may be paid at once or split into multiple payments. We assumed that physicians who lacked payment information in the Open Payments database had not received payments from industry.

\section{Statistical analyses}

First, we analysed the concentration of total industry payments across physicians. We also ranked physicians by total value of payments received from industry and determined the proportion of total industry payments that were concentrated among physicians in the top $1 \%$ and $5 \%$ of all physicians by size of total industry payments from 2015 to 2017.

Second, we examined the association between physician characteristics and annual total industry payment value by constructing multivariable negative binomial regression models (to account for a right-skewed distribution of industry payments), adjusting for other physician characteristics and institution fixed effects. Physician characteristics evaluated in this model included sex, years in practice, medical school attended and clinical specialty. Institution fixed effects-indicator variables for each institution identified using each physician's primary practice address-were included to account for both measured and unmeasured characteristics of institutions that do not vary over time, effectively allowing us to compare physicians practicing in the same institution. ${ }^{28-30}$ The unit of analysis was physicians and SEs were clustered at the institution level to account for potential correlations between physicians practicing in the same institution. ${ }^{31}$ To calculate adjusted industry payment values for each group of physicians, after fitting regression models, we estimated predicted payment value for each physician, fixing physician characteristics at each level of the categories and averaged over our national sample (known as the marginal standardisation form of predictive margins, predictive margins, or margins of responses). ${ }^{32}$

Finally, we used a similar approach to that employed in our analysis of total industry payments to estimate associations between individual physician characteristics and the magnitude of each payment type separately (ie, general payments, research payments and ownership interests). For the analysis of general payments, as the industry marketing to physicians for drugs may have a different pattern than that for devices, we also conducted the analysis restricting to the payments made for drugs. For the analyses of research payments and ownership interests, given that the majority of physicians were receiving zero payment $(98.3 \%$ and $99.5 \%$ of physicians were not receiving any research payments and ownership interests, respectively), we used two-part regression models ${ }^{33}$ and evaluated physician characteristics associated with the odds of receiving any payments, as well as adjusted payment values for physicians who were receiving any payments (the first part was a logistic regression model estimating non-zero payments and the second part was a negative binomial regression model estimating the value of payments). For the analysis of ownership interests, we categorised physicians into four different specialties (primary care, surgery, specialists and others) to avoid unstable estimates due to smaller sample size.

\section{Sensitivity analyses}

We conducted sensitivity analyses for the analysis of total industry payments. First, to evaluate if our definitions of industry payments impacted our findings, we conducted multivariable logistic regression analyses using alternative definitions of industry payments: (1) whether physicians received any industry payments and (2) whether physicians received industry payments greater than $\$ 5000$ (because the US Department of Health and Human Services specifically identifies payments exceeding this threshold as significant financial interests that require disclosure). Second, to test the impact of how we specify the distribution of payment data, we used alternative model specifications: (1) a two-part model ${ }^{33}$ (the first part was a logistic regression model, estimating non-zero payments and the second part was a negative binomial regression model, estimating the value of payments) and (2) ordinary least square regression with Huber-White heteroscedasticity-robust SEs. Last, to evaluate the generalisability of our primary analysis to physicians who do not treat Medicare beneficiaries (and therefore, not included in the Physician Compare database), we examined the association between physician characteristics included in the Open Payments-NPPES linked database (physician sex and specialty) and the value of industry payments, without restricting physicians included in the Physician Compare database. All analyses were conducted using Stata, V.15 (Stata).

\section{Patient and public involvement}

No patients were involved in setting the research question or the outcome measures, nor were they involved in developing plans for design or implementation of the study. No patients were asked to advise on interpretation or writing up of results. There are no plans to disseminate the results of the research to study participants or the relevant patient community.

\section{RESULTS}

Of 544264 physicians who were treating Medicare beneficiaries, a total of $\$ 5.8$ billion in industry payments were made to 365801 physicians in 2015-2017, with a median (IQR) annual payment value of \$199 (\$42-\$878). About $68 \%(370549 / 544264)$ of physicians were male and mean (SD) years in practice was 23 (12) years (table 1). Industry payments were concentrated among a small number of physicians who accounted for a large share 
of the total amount of payments (online supplementary figure 2). The top $1 \%$ and $5 \%$ of physicians accounted for $73 \%$ and $91 \%$ of total industry payments, respectively.

\section{Association between physician characteristics and the value of total industry payments}

After adjusting for other physician characteristics and institution fixed effects, male physicians received significantly larger value of industry payments than female physicians (adjusted annual payment value, $\$ 4164$ for male vs $\$ 1650$ for female; adjusted \% difference, $+152 \%$; $95 \%$ CI $+85 \%$ to $+244 \%$; $\mathrm{p}<0.001$ ) meaning that the average male physicians had payments totalling 2.5 times that of female physicians (table 2). Physicians with 21-30 years in practice, received the largest payments, $\$ 5231$ (adjusted annual payment value), followed by $\$ 3878$, for $>30$ years, $\$ 3180$, for $11-20$ years and $\$ 906$, for those with $\leq 10$ years in practice. Physicians who attended US medical schools ranked below 50 or foreign medical schools, received lower payments compared with physicians who attended top 20 research medical schools.

After adjusting for other physician characteristics, orthopaedic surgeons received the highest payments (adjusted payment value, $\$ 18650 ; 95 \%$ CI $\$ 14475$ to $\$ 22$ 826 ), followed by neurosurgeons ( $\$ 15937 ; 95 \%$ CI $\$ 7861$ to $\$ 24012$ ) and endocrinologists ( $\$ 11829 ; 95 \%$ CI $\$ 9350$ to $\$ 14309$ ) (table 2). Hospitalists received the lowest payments ( $\$ 312$; $95 \%$ CI $\$ 212$ to $\$ 412$ ), followed by paediatricians ( $\$ 1050$; $95 \%$ CI $\$ 742$ to $\$ 1359$ ) and anaesthesiologists ( $\$ 1106 ; 95 \%$ CI $\$ 836$ to $\$ 1375)$.

\section{General payments}

A total of 365441 physicians treating Medicare beneficiaries, received general payments in 2015-2017, with a median (IQR) annual payment value of \$195 (\$42-\$852). Our results for general payments were similar to total payments (suggesting that our findings for total payments were driven largely by general payments). We found that general payments were higher for male physicians, physicians with 21-30 years in practice and physicians who attended top 20 research medical schools (table 3A). Physicians in orthopaedic, neurosurgery and endocrinology received the highest payments, while hospitalists, emergency physicians and anaesthesiologists received the lowest general payments. When we restricted our analysis to payments for drugs and not for devices, we also observed the highest amount of industry payments were made to endocrinologists, but not to physicians in orthopaedic and neurosurgery (online supplementary table 1 ).

\section{Research payments}

A total of 9456 physicians treating Medicare beneficiaries received research payments in 2015-2017, with a median (IQR) annual payment value of $\$ 827$ ( $\$ 233$ to $\$ 3667$ ). We found that male physicians, physicians practicing for more than 10 years and physicians who attended top 20 medical schools, were associated with the receiving research payments (table 3B). Haematologists/ oncologists, allergists/immunologists, rheumatologists and endocrinologists were the most likely to receive research payments, while hospitalists, anaesthesiology and physicians in rehabilitation, were the least likely. Among physicians receiving any research payments, allergists/ immunologists received the largest research payments.

\section{Ownership interests}

A total of 2648 physicians treating Medicare beneficiaries received ownership interests in 2015-2017, with a median (IQR) annual value of \$17002 (\$1324-\$73 567). We found that male physicians, physicians practicing for more than 10 years, and physicians who attended top 50 medical schools, were associated with the receiving ownership interests (table 3C). Across specialties, surgeons were receiving higher ownership interests than other types of physicians, including specialists and primary care physicians.

\section{Sensitivity analyses}

Our findings were not qualitatively affected using alternative definitions of industry payments (online supplementary tables 2 and 3), and alternative specification of the distribution of payment data (online supplementary tables 4 and 5). Physicians and specialties were similar to physicians who were included in the Physician Compare database and those who were not (online supplementary tables 6) and our findings were similar when we analysed the data without restricting our study cohort to physicians included in the Physician Compare database (online supplementary tables 7 ).

\section{DISCUSSION}

Using payment data from industry to physicians in 2015-2017 in the CMS Open Payments database linked with comprehensive data on practicing physicians in the U.S., we found that industry payments were concentrated among a small number of physicians; the top $5 \%$ of physicians by total payment value accounted for $91 \%$ of total industry payments to physicians in 2015-2017. We also found that, within the same institution, male sex, physicians who have more years in practice and those who graduated from medical schools with highly-ranked research programmes, were associated with higher total value of industry payments. Across specialties, orthopaedic surgeons, neurosurgeons and endocrinologists received the highest total industry payments. Taken together, these findings extend our understanding of the financial relationships between industry and US practicing physicians and how industry payments to physicians may influence prescribing practices.

These findings have important policy implications. Although the total number of industry payments to physicians has declined recently, ${ }^{18}{ }^{34}$ the total dollar value of payments remains as high as $\$ 8.4$ billion, ${ }^{34}$ indicating that improved transparency through the Physician Payments Sunshine Act alone may not be adequate to change how industry interact with physicians. Our findings suggest 
Table 2 Comparison of industry total payment value according to physician characteristics

Mean value of payments

\begin{tabular}{llll}
\hline Unadjusted & Adjusted $(95 \% \mathrm{Cl})$ & Adjusted $\%$ difference $(95 \% \mathrm{Cl}) \quad \mathrm{P}$ value
\end{tabular}

Sex

$\begin{array}{lllll}\text { Female } & \$ 1090 & \$ 1650(1149 \text { to } 2151) & \text { Ref } & - \\ \text { Male } & \$ 4735 & \$ 4164(3304 \text { to } 5025) & +152 \%(+85 \% \text { to+244\%) } & <0.001\end{array}$

Years in practice

\begin{tabular}{|c|c|c|c|c|}
\hline$\leq 10$ & $\$ 632$ & $\$ 906$ (663 to 1148 ) & Ref & - \\
\hline $11-20$ & $\$ 2712$ & $\$ 3180$ (2420 to 3941$)$ & $+251 \%$ (+135\% to+424\%) & $<0.001$ \\
\hline $21-30$ & $\$ 5160$ & $\$ 5231$ (3495 to 6966) & $+478 \%(+304 \%$ to $+726 \%)$ & $<0.001$ \\
\hline$>30$ & $\$ 4930$ & $\$ 3878$ (3342 to 4414$)$ & $+328 \%$ (+228\% to+460\%) & $<0.001$ \\
\hline \multicolumn{5}{|l|}{ Medical school attended* } \\
\hline Top 20 school in USA & $\$ 5249$ & $\$ 3759$ (3265 to 4254) & Ref & - \\
\hline US schools ranked $21-50$ & $\$ 5527$ & $\$ 5477$ (2604 to 8350) & $+46 \%(-8 \%$ to $+131 \%)$ & 0.11 \\
\hline Other schools & $\$ 2830$ & $\$ 3003$ (2687 to 3320) & $-20 \%(-31 \%$ to $-7 \%)$ & 0.004 \\
\hline \multicolumn{5}{|l|}{ Specialty } \\
\hline \multicolumn{5}{|l|}{ Primary care } \\
\hline Internal Medicine & $\$ 1747$ & $\$ 2641$ (1260 to 4022$)$ & Ref & - \\
\hline Family Medicine & $\$ 2590$ & $\$ 1515$ (323 to 2706$)$ & $-43 \%(-73 \%$ to $+23 \%)$ & 0.15 \\
\hline Paediatrics & $\$ 669$ & $\$ 1050$ (742 to 1359) & $-60 \%(-78 \%$ to $-27 \%)$ & 0.003 \\
\hline Hospitalist & $\$ 208$ & $\$ 312$ (212 to 412$)$ & $-88 \%(-94 \%$ to $-78 \%)$ & $<0.001$ \\
\hline \multicolumn{5}{|l|}{ Surgery } \\
\hline Orthopaedic & $\$ 23897$ & $\$ 18650$ (14475 to 22826$)$ & $+606 \%$ (+327\% to+1067\%) & $<0.001$ \\
\hline Neurosurgery & $\$ 20156$ & $\$ 15937$ (7861 to 24012) & $+503 \%(+204 \%$ to $+1098 \%)$ & $<0.001$ \\
\hline Thoracic/Vascular & $\$ 5804$ & $\$ 4580$ (3473 to 5686$)$ & $+73 \%$ (+3\% to+192\%) & 0.04 \\
\hline Urology & $\$ 4849$ & $\$ 4381$ (3461 to 5300$)$ & $+66 \%(-3 \%$ to $+182 \%)$ & 0.06 \\
\hline Colorectal & $\$ 3417$ & $\$ 3252$ (2300 to 4204) & $+23 \%(-32 \%$ to $+122 \%)$ & 0.49 \\
\hline General & $\$ 2791$ & $\$ 2983$ (2294 to 3672) & $+13 \%(-35 \%$ to $+95 \%)$ & 0.66 \\
\hline Plastic & $\$ 2650$ & $\$ 2467$ (1894 to 3040) & $-7 \%(-47 \%$ to $+64 \%)$ & 0.81 \\
\hline Otolaryngology & $\$ 1400$ & $\$ 1333$ (1062 to 1604$)$ & $-50 \%(-70 \%$ to $-14 \%)$ & 0.01 \\
\hline Obstetrics/Gynaecology & $\$ 932$ & $\$ 1249$ (921 to 1578) & $-53 \%(-74 \%$ to $-15 \%)$ & 0.01 \\
\hline \multicolumn{5}{|l|}{ Specialists } \\
\hline Endocrinology & $\$ 11327$ & $\$ 11829$ (9350 to 14309$)$ & $+348 \%$ (+152\% to+695\%) & $<0.001$ \\
\hline Rheumatology & $\$ 7252$ & $\$ 8049$ (5982 to 10117$)$ & $+205 \%$ (+73\% to+436\%) & $<0.001$ \\
\hline Haematology/Oncology & $\$ 7578$ & $\$ 7676$ (6288 to 9063$)$ & $+191 \%$ (+68\% to+402\%) & $<0.001$ \\
\hline Neurology & $\$ 6244$ & $\$ 7592$ (5938 to 9247) & $+188 \%$ (+65\% to $+402 \%)$ & $<0.001$ \\
\hline Dermatology & $\$ 4239$ & $\$ 5238$ (4169 to 6307 ) & +98\% (+12\% to+251\%) & 0.02 \\
\hline Cardiology & $\$ 6024$ & $\$ 4932$ (4219 to 5646 ) & $+87 \%(+15 \%$ to+204\%) & 0.01 \\
\hline Allergy/Immunology & $\$ 4625$ & $\$ 4729$ (3582 to 5876$)$ & $+79 \%$ (+3\% to+211\%) & 0.04 \\
\hline Ophthalmology & $\$ 4659$ & $\$ 4487$ (2406 to 6568) & $+70 \%(-13 \%$ to $+232 \%)$ & 0.12 \\
\hline Gastroenterology & $\$ 4214$ & $\$ 3730$ (3026 to 4434$)$ & $+41 \%(-16 \%$ to $+138 \%)$ & 0.20 \\
\hline Infectious Diseases & $\$ 2713$ & $\$ 2658$ (2034 to 3281 ) & $+1 \%(-44 \%$ to $+80 \%)$ & 0.98 \\
\hline Pulmonology & $\$ 2889$ & $\$ 2462$ (2020 to 2904) & $-7 \%(-45 \%$ to $+57 \%)$ & 0.79 \\
\hline Paediatric Specialty & $\$ 1877$ & $\$ 1970$ (1412 to 2528) & $-25 \%(-59 \%$ to $+35 \%)$ & 0.33 \\
\hline Psychiatry & $\$ 1722$ & $\$ 1852$ (1229 to 2476) & $-30 \%(-62 \%$ to $+29 \%)$ & 0.25 \\
\hline Radiology & $\$ 2141$ & $\$ 1854$ (1340 to 2368) & $-30 \%(-60 \%$ to $+22 \%)$ & 0.21 \\
\hline Nephrology & $\$ 1825$ & $\$ 1694$ (1188 to 2199$)$ & $-36 \%(-64 \%$ to $+13 \%)$ & 0.12 \\
\hline
\end{tabular}

Continued 


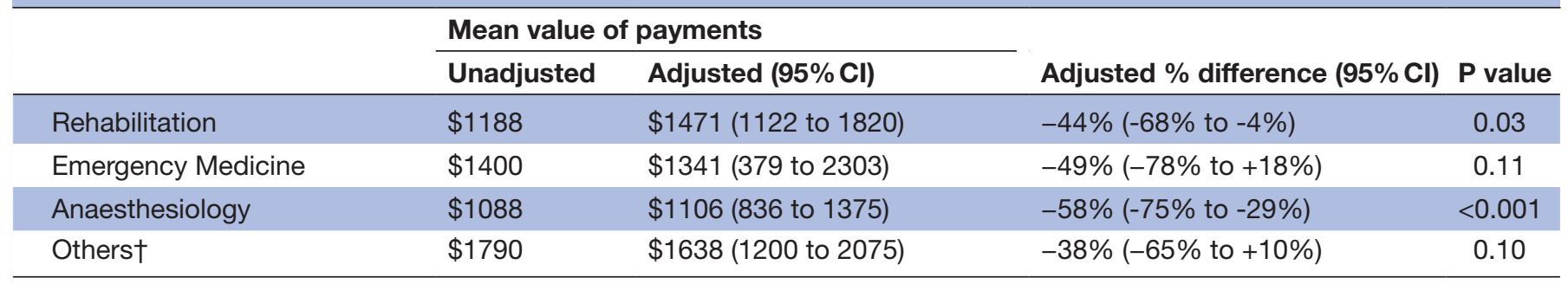

${ }^{*}$ Defined based on the U.S. News \& World Report ranking (research ranking) in 2017.

†Others include surgical oncology, oral surgery, radio oncology, pathology, nuclear medicine and so on.

that industry may be targeting certain types of physicians-who are likely to be key thought leaders, content experts and clinical experts-who themselves may be prescribing a large amount of medications, or who may be influential in changing prescription practices of other physicians. Therefore, our findings should be informative for policymakers to design policies that can effectively minimise the influence of industry on medical practice. Further longitudinal studies are warranted to investigate the causal effect of industry marketing on physician prescriptions and patient outcome.

Extensive research has shown that even small financial or in-kind gifts or compensation from industry may affect physicians' decision-making. ${ }^{1535}$ Yet, less is known about physician characteristics associated with receipt of larger industry payments. Prior studies included physician sex, ${ }^{14-16}$ years in practice, ${ }^{16} 18$ and clinical specialty ${ }^{1015} 16$ as physician-level covariates. Therefore, if there is a difference in sex distribution according to medical school research ranking, for example, then failing to adjust for medical school attended could lead to biased results. Our findings indicate that, even after adjustment for years in practice, medical school attended and specialty, male sex was still associated with larger payments from industry. This finding may be explained by the fact that female physicians may have different preferences for industry engagement ${ }^{36}$ or that they may be less likely to negotiate for higher payments when they do engage with industry. ${ }^{14}$

Our findings indicate that physicians with more years in practice received higher payments from industry, compared with less experienced physicians, which is consistent with the recent findings using the 2014-2016 Open Payments data. ${ }^{18}$ These findings may reflect the fact that industry is most interested in building relationships with physicians who are experts in their field given that such expertise and experience can be obtained over many years of work in research and/or clinical practice. ${ }^{37}$ Our finding that physicians who attended elite research medical schools on average, received higher industry payments than physicians who attended less prestigious research medical schools is also a new finding and may reflect these same tendencies.

We found that orthopaedic surgeons, neurosurgeons and endocrinologists received higher industry payments (both total and general payments) than physicians from other specialties, even after adjusting for other physician characteristics, including age and clinical experience. Meanwhile, we found that orthopaedic surgeons and neurosurgeons received fewer general payments from the industry when we restricted to general payments for drugs (ie, excluding general payments for devices). These results indicate that high industry payments to orthopaedic surgeons and neurosurgeons likely reflect payments from the medical device industry, a finding that has been previously demonstrated ${ }^{38-40}$ Endocrinologists may receive higher payments from industry because they are centrally involved in treating several highly prevalent and expensive chronic diseases, including diabetes, hyperlipidaemia and obesity. Drug and medical device companies generate large amounts of revenue from treatments targeting these diseases. In 2017, for example, there were 25 (non-insulin) glucose-lowering agents among 11 classes of therapies, creating a highly-competitive market for medications used by endocrinologists. ${ }^{41}$ This hypothesis is supported by a recent study of industry payments to journal editors, which suggested that editors of endocrinology journals receive higher industry payments than editors of journals focused on other medical specialties. ${ }^{42}$

Our study has limitations. First, although the quality of Open Payments data has improved over time, ${ }^{13}$ it is still possible that the database has inaccuracies about the value of payments actually received by physicians. The Open Payments Data, however, are the most comprehensive and reliable data of industry payments to physicians available and the CMS encourages all physicians to review and dispute incorrect information prior to publication and nearly $30 \%$ of the total value of 2014 payments were actually reviewed. ${ }^{13}$ Second, our sample did not include physicians who had no Medicare claims, and, therefore, these findings may not be generalisable to physicians not caring for Medicare beneficiaries. However, our findings were not qualitatively affected by inclusion of all physicians regardless of whether they were treating Medicare beneficiaries in sensitivity analyses. Third, although we included an extensive set of physician characteristics in our regression models, we could not rule out the possibility of residual confounding, due to unmeasured physician characteristics, not included in our analyses. Last, it is possible that pharmaceutical and medical device companies underreport the value of payments to physicians. 
Table 3A Comparison of industry general payment value according to physician characteristics

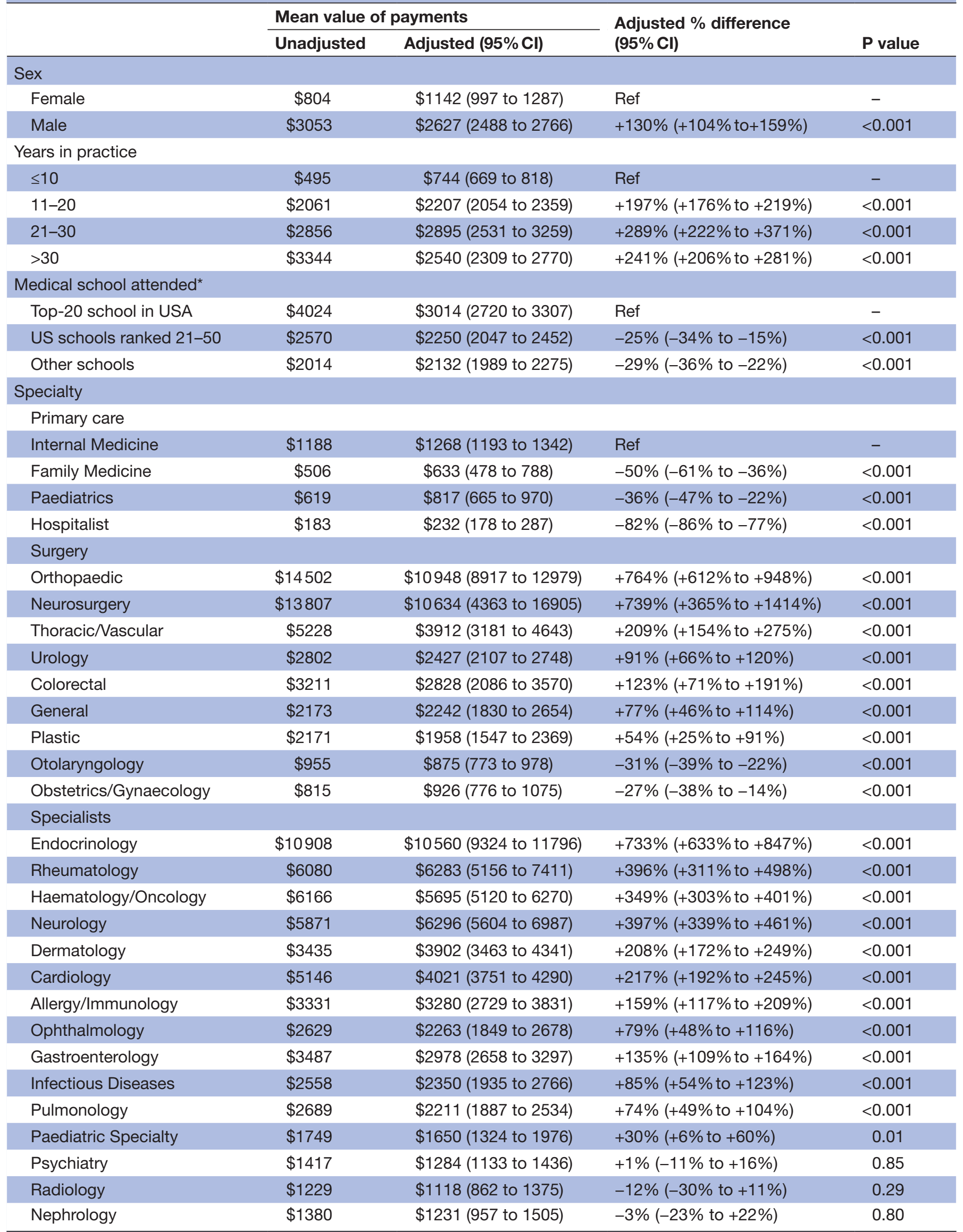


Table 3A Continued

\begin{tabular}{|c|c|c|c|c|}
\hline & \multicolumn{2}{|c|}{ Mean value of payments } & \multirow{2}{*}{$\begin{array}{l}\text { Adjusted \% difference } \\
(95 \% \mathrm{Cl})\end{array}$} & \multirow[b]{2}{*}{$P$ value } \\
\hline & Unadjusted & Adjusted $(95 \% \mathrm{Cl})$ & & \\
\hline Rehabilitation & $\$ 1059$ & $\$ 1166$ (975 to 1358$)$ & $-8 \%(-22 \%$ to $+9 \%)$ & 0.34 \\
\hline Emergency Medicine & $\$ 668$ & $\$ 592$ (512 to 672$)$ & $-53 \%(-59 \%$ to $-46 \%)$ & $<0.001$ \\
\hline Anaesthesiology & $\$ 669$ & $\$ 671$ (573 to 769 ) & $-47 \%(-55 \%$ to $-38 \%)$ & $<0.001$ \\
\hline Others $\dagger$ & $\$ 1190$ & $\$ 1122$ (856 to 1388 ) & $-12 \%(-30 \%$ to $+12 \%)$ & 0.31 \\
\hline
\end{tabular}

*Defined based on the U.S. News \& World Report ranking (research ranking) in 2017.

†Others include surgical oncology, oral surgery, radio oncology, pathology, nuclear medicine and so on.

Table 3B OR of receiving research payments and comparison of the received payment value according to physician characteristics

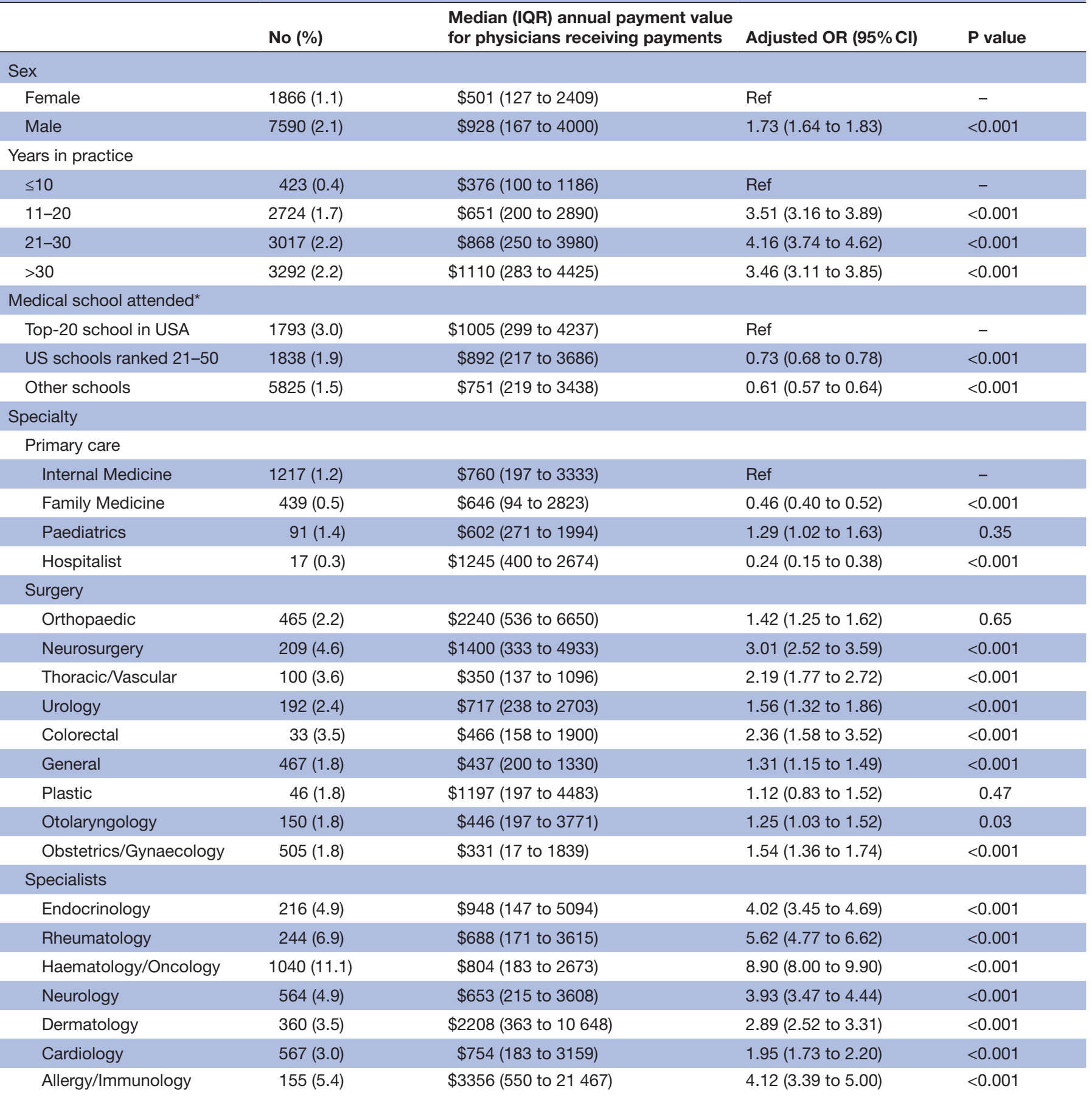

Continued 
Table 3B Continued

\begin{tabular}{|c|c|c|c|c|}
\hline & No (\%) & $\begin{array}{l}\text { Median (IQR) annual payment value } \\
\text { for physicians receiving payments }\end{array}$ & Adjusted OR (95\% Cl) & $P$ value \\
\hline Ophthalmology & $476(3.0)$ & $\$ 1311$ (418 to 5745 ) & 2.09 (1.83 to 2.38$)$ & $<0.001$ \\
\hline Gastroenterology & $361(3.5)$ & $\$ 1667$ (386 to 4330$)$ & 2.33 (2.01 to 2.69 ) & $<0.001$ \\
\hline Infectious Diseases & $94(2.0)$ & $\$ 1102$ (290 to 3770 ) & $1.50(1.21$ to 1.85$)$ & $<0.001$ \\
\hline Pulmonology & $122(2.2)$ & $\$ 795$ (280 to 3902$)$ & 1.51 (1.23 to 1.85$)$ & $<0.001$ \\
\hline Paediatric Specialty & $138(3.9)$ & $\$ 479$ (180 to 1130$)$ & 3.00 (2.49 to 3.61$)$ & $<0.001$ \\
\hline Psychiatry & $240(1.1)$ & $\$ 1344$ (459 to 7083 ) & 0.87 (0.74 to 1.01$)$ & 0.07 \\
\hline Radiology & $241(1.0)$ & $\$ 2206$ (525 to 7206 ) & 0.68 (0.57 to 0.82 ) & $<0.001$ \\
\hline Nephrology & $141(2.0)$ & $\$ 604$ (263 to 3550) & 1.46 (1.21 to 1.76$)$ & $<0.001$ \\
\hline Rehabilitation & $34(0.5)$ & $\$ 909$ (188 to 3812$)$ & 0.37 (0.26 to 0.53 ) & $<0.001$ \\
\hline Emergency Medicine & $122(0.7)$ & $\$ 567$ (228 to 2000 ) & 0.50 (0.41 to 0.61$)$ & $<0.001$ \\
\hline Anaesthesiology & $124(0.3)$ & $\$ 1343$ (399 to 4042) & 0.25 (0.21 to 0.31$)$ & $<0.001$ \\
\hline Others $†$ & $286(1.0)$ & $\$ 728$ (233 to 2493 ) & 0.76 (0.66 to 0.87$)$ & $<0.001$ \\
\hline
\end{tabular}

*Defined based on the U.S. News \& World Report ranking (research ranking) in 2017.

tOthers include surgical oncology, oral surgery, radio oncology, pathology, nuclear medicine and so on.

Table $3 \mathrm{C}$ OR of receiving ownership interests and comparison of the received payment value according to physician characteristics

\begin{tabular}{|c|c|c|c|c|}
\hline Value invested & No (\%) & $\begin{array}{l}\text { Median (IQR) annual } \\
\text { payment value for } \\
\text { physicians receiving } \\
\text { payments }\end{array}$ & Adjusted OR $(95 \% \mathrm{Cl})$ & $P$ value \\
\hline \multicolumn{5}{|l|}{ Sex } \\
\hline Female & $305(0.2)$ & $\$ 33$ (7 to 200$)$ & Ref & Ref \\
\hline Male & $1995(0.5)$ & $\$ 6000$ (192 to 75 595) & 2.20 (1.92 to 2.51$)$ & $<0.001$ \\
\hline \multicolumn{5}{|l|}{ Years in practice } \\
\hline$\leq 10$ & $48(0.1)$ & $\$ 3991$ (6 to 22 954) & Ref & Ref \\
\hline $11-20$ & $525(0.3)$ & $\$ 6667$ (193 to 25000$)$ & 6.30 (4.67 to 8.49 ) & $<0.001$ \\
\hline $21-30$ & $806(0.6)$ & $\$ 4686$ (280 to 35217 ) & 9.99 (7.48 to 13.35$)$ & $<0.001$ \\
\hline$>30$ & $921(0.6)$ & $\$ 4686$ (289 to 39250$)$ & 9.68 (7.24 to 12.95$)$ & $<0.001$ \\
\hline \multicolumn{5}{|l|}{ Medical school attended ${ }^{\star}$} \\
\hline Top 20 school in USA & $365(0.6)$ & $\$ 10000$ (755 to 33339$)$ & Ref & Ref \\
\hline US schools ranked $21-50$ & $545(0.6)$ & $\$ 6202$ (370 to 33667 ) & $1.00(0.87$ to 1.15$)$ & 0.96 \\
\hline Other schools & $1390(0.4)$ & $\$ 4500$ (192 to 32 109) & 0.75 (0.66 to 0.85$)$ & $<0.001$ \\
\hline \multicolumn{5}{|l|}{ Specialty } \\
\hline Primary care & $367(0.2)$ & $\$ 20$ (7 to 57$)$ & Ref & Ref \\
\hline Surgery & $1275(1.2)$ & $\$ 8333$ (425 to 38155$)$ & 5.44 (4.58 to 6.46$)$ & $<0.001$ \\
\hline Specialists & $584(0.3)$ & $\$ 14495$ (1667 to 52500$)$ & 1.18 (0.98 to 1.43$)$ & 0.09 \\
\hline Others $†$ & $74(0.3)$ & $\$ 17027$ (3333 to 53 972) & $1.18(0.87$ to 1.61$)$ & 0.29 \\
\hline Value of interest & No (\%) & $\begin{array}{l}\text { Median (IQR) annual } \\
\text { payment value for } \\
\text { physicians receiving } \\
\text { payments }\end{array}$ & Adjusted OR $(95 \% \mathrm{Cl})$ & $P$ value \\
\hline \multicolumn{5}{|l|}{ Sex } \\
\hline Female & $318(0.2)$ & $\$ 89$ (11 to 11591$)$ & Ref & Ref \\
\hline Male & $2154(0.6)$ & $\$ 13890$ (1944 to 52247$)$ & 2.31 (2.03 to 2.63 ) & $<0.001$ \\
\hline \multicolumn{5}{|l|}{ Years in practice } \\
\hline$\leq 10$ & $51(0.1)$ & $\$ 5649$ (11 to 30604 ) & Ref & Ref \\
\hline
\end{tabular}

Continued 


\begin{tabular}{|c|c|c|c|c|}
\hline Value invested & No (\%) & $\begin{array}{l}\text { Median (IQR) annual } \\
\text { payment value for } \\
\text { physicians receiving } \\
\text { payments }\end{array}$ & Adjusted OR (95\% Cl) & $P$ value \\
\hline $11-20$ & $582(0.4)$ & $\$ 10625$ (755 to 30882$)$ & 6.53 (4.90 to 8.71$)$ & $<0.001$ \\
\hline $21-30$ & $901(0.7)$ & $\$ 11067$ (1100 to 46933 ) & 10.39 (7.86 to 13.74$)$ & $<0.001$ \\
\hline$>30$ & $938(0.6)$ & $\$ 12062$ (1820 to 57 265) & 9.13 (6.89 to 12.09$)$ & $<0.001$ \\
\hline \multicolumn{5}{|l|}{ Medical school attended* } \\
\hline Top 20 school in USA & $420(0.7)$ & $\$ 11052$ (1995 to 41805) & Ref & Ref \\
\hline US schools ranked $21-50$ & $588(0.6)$ & $\$ 12250$ (1667 to 50143 ) & 0.94 (0.83 to 1.07$)$ & 0.35 \\
\hline Other schools & $1464(0.4)$ & $\$ 10360$ (660 to 42659$)$ & 0.69 (0.61 to 0.78$)$ & $<0.001$ \\
\hline \multicolumn{5}{|l|}{ Specialty } \\
\hline Otherst & $76(0.3)$ & $\$ 17707$ (2504 to 70084$)$ & 1.18 (0.87 to 1.59$)$ & 0.28 \\
\hline
\end{tabular}

*Defined based on the U.S. News \& World Report ranking (research ranking) in 2017.

†Others include surgical oncology, oral surgery, radio oncology, pathology, nuclear medicine and so on.

\section{CONCLUSION}

Using a contemporary national database of industry payments to physicians in 2015-2017, linked to a comprehensive database of practicing US physicians, we found that male physicians, more experienced physicians and physicians from medical schools with highly-ranked research programmes were more likely to receive higher payments from industry than other physicians. In addition, orthopaedic surgeons, neurosurgeons and endocrinologists received larger overall payments from industry than did other types of clinicians. These findings highlight that promotional activities of the industry target clinician-scientists in specific specialties with sufficient clinical experience to influence prescribing practices.

\section{Author affiliations}

${ }^{1}$ Epidemiology, UCLA Fielding School of Public Health, Los Angeles, California, USA

${ }^{2}$ Cardiology, Massachusetts General Hospital, Boston, Massachusetts, USA

${ }^{3}$ Department of Medicine, Harvard Medical School, Boston, Massachusetts, USA

${ }^{4}$ Devoted Health, Waltham, Massachusetts, USA

${ }^{5}$ Biostatistics, UCLA Fielding School of Public Health, Los Angeles, California, USA

${ }^{6}$ Department of Medicine Statistics Core, UCLA David Geffen School of Medicine,

Los Angeles, California, USA

${ }^{7}$ General Internal Medicine and Health Services Research, UCLA David Geffen

School of Medicine, Los Angeles, California, USA

${ }^{8}$ Department of Health Policy Management, UCLA Fielding School of Public Health, Los Angeles, California, USA

Contributors All authors had full access to all the data in the study and take responsibility for the integrity of the data and the accuracy of the data analysis. Concept and design: KI, YT. Acquisition, analysis or interpretation of data: KI, YT. Drafting of the manuscript: KI, DMB, DE, YT. Critical revision of the manuscript for important intellectual content: KI, DMB, DE, YT. Statistical analysis: KI, DE, YT.

Funding KI was supported by the Burroughs Wellcome Fund Interschool Training Program in Chronic Diseases (BWF-CHIP), a Fellowship in Epidemiology at UCLA and Heiwa Nakajima Foundation.
Disclaimer Study sponsors were not involved in study design, data interpretation, writing or the decision to submit the article for publication.

Competing interests All authors have completed the ICMJE uniform disclosure format (available on request from the corresponding author) and declare: DMB has received consulting fees unrelated to this work from Precision Health Economics, Amgen, Novartis and HLM Venture Partners and is the Associate Chief Medical Officer of Devoted Health, which is a health insurance company.

Patient consent for publication Not required.

Ethics approval The study was approved by the institutional review board (Human Research Protection Program) at University of California, Los Angeles (IRB\#18-001960).

Provenance and peer review Not commissioned; externally peer reviewed. Data availability statement Data are available in a public, open access repository. Open access This is an open access article distributed in accordance with the Creative Commons Attribution Non Commercial (CC BY-NC 4.0) license, which permits others to distribute, remix, adapt, build upon this work non-commercially, and license their derivative works on different terms, provided the original work is properly cited, appropriate credit is given, any changes made indicated, and the use is non-commercial. See: http://creativecommons.org/licenses/by-nc/4.0/.

\section{REFERENCES}

1. DeJong C, Aguilar T, Tseng C-W, et al. Pharmaceutical industrysponsored meals and physician prescribing patterns for Medicare beneficiaries. JAMA Intern Med 2016;176:1114-22.

2. Mitchell AP, Winn AN, Dusetzina SB. Pharmaceutical Industry Payments and Oncologists' Selection of Targeted Cancer Therapies in Medicare Beneficiaries. JAMA Intern Med 2018;178:854-6.

3. Fleischman W, Agrawal S, King M, et al. Association between payments from manufacturers of pharmaceuticals to physicians and regional prescribing: cross sectional ecological study. BMJ 2016;354

4. Yeh JS, Franklin JM, Avorn J, et al. Association of industry payments to physicians with the prescribing of brand-name statins in Massachusetts. JAMA Intern Med 2016;176:763-8.

5. Bekelman JE, Li Y, Gross CP. Scope and impact of financial conflicts of interest in biomedical research: a systematic review. JAMA 2003;289:454-65.

6. Institute of Medicine (US) Committee on Conflict of Interest in Medical Research, Education, and PracticeLo B, Field MJ, eds. Conflict of interest in medical research, education, and practice. 
Washington (DC: National Academies Press (US), 2009. http://www. ncbi.nlm.nih.gov/books/NBK22942/

7. Morse E, Fujiwara RJT, Mehra S. The association of industry payments to physicians with prescription of brand-name intranasal corticosteroids. Otolaryngol Head Neck Surg 2018;159:442-8.

8. Modi PK, Wang Y, Kirk PS, et al. The receipt of industry payments is associated with prescribing promoted Alpha-blockers and overactive bladder medications. Urology 2018;117:50-6.

9. Sharma M, Vadhariya A, Johnson ML, et al. Association between industry payments and prescribing costly medications: an observational study using open payments and Medicare Part D data. BMC Health Serv Res 2018;18:236.

10. Marshall DC, Jackson ME, Hattangadi-Gluth JA. Disclosure of industry payments to physicians: an epidemiologic analysis of early data from the open payments program. Mayo Clin Proc 2016;91:84-96

11. Taylor SC, Huecker JB, Gordon MO, et al. Physician-Industry interactions and anti-vascular endothelial growth factor use among US ophthalmologists. JAMA Ophthalmol 2016;134:897-903.

12. Kirschner NM, Sulmasy LS, Kesselheim AS. Health policy basics: the physician payment sunshine act and the open payments program. Ann Intern Med 2014;161:519-21.

13. Agrawal S, Brown D. The physician payments sunshine act--two years of the open payments program. N Engl J Med 2016;374:906-9.

14. Tringale KR, Hattangadi-Gluth JA. Types and distributions of biomedical industry payments to men and women physicians by specialty, 2015. JAMA Intern Med 2018;178:421-3.

15. Tringale KR, Marshall D, Mackey TK, et al. Types and distribution of payments from industry to physicians in 2015. JAMA 2017;317:1774-84.

16. Campbell EG, Gruen RL, Mountford J, et al. A national survey of Physician-Industry relationships. N Engl J Med Overseas Ed 2007;356:1742-50.

17. Reddy AK, Bounds GW, Bakri SJ, et al. Representation of women with industry ties in ophthalmology. JAMA Ophthalmol 2016;134:636-43.

18. Brunt CS. Physician characteristics, industry transfers, and pharmaceutical prescribing: empirical evidence from Medicare and the physician payment sunshine act. Health Serv Res 2019;54:636-49.

19. Marshall DC, Moy B, Jackson ME, et al. Distribution and patterns of Industry-Related payments to oncologists in 2014. J Natl Cancer Inst 2016;108:djw163.

20. Khan MS, Siddiqi TJ, Fatima K, et al. Evaluation of industrial compensation to cardiologists in 2015. Am J Cardiol 2017;120:2294-8.

21. Schnell M, Currie J. Addressing the opioid epidemic: is there a role for physician education? Am J Health Econ 2018;4:383-410.

22. STAT. Purdue pharma cemented ties with universities and hospitals. Available: https://www.statnews.com/2019/01/16/purdue-pharmacemented-ties-to-universities-hospitals/ [Accessed 4 Feb 2019].

23. NPR.org. Massachusetts attorney General implicates family behind Purdue pharma in opioid deaths. Available: https://www.npr.org/ sections/health-shots/2019/01/16/685692474/massachusettsattorney-general-implicates-family-behind-purdue-pharma-in-opioid[Accessed 4 Feb 2019].

24. The Boston Globe. Five things you should know about the mass. suit targeting OxyContin maker Purdue pharma. Available: https://www. bostonglobe.com/metro/2019/01/16/five-things-you-should-knowabout-mass-suit-targeting-oxycontin-maker-purdue-pharma/fpzy qU92oidRSz7SBUqdiK/story.html [Accessed 4 Feb 2019].

25. Data.Medicare.gov. Datasets. Available: https://data.medicare.gov/ data/physician-compare [Accessed 6 Jan 2019].

26. Tsugawa Y, Blumenthal DM, Jha AK, et al. Association between physician US News \& World Report medical school ranking and patient outcomes and costs of care: observational study. BMJ 2018;362.

27. Reid RO, Friedberg MW, Adams JL, et al. Associations between physician characteristics and quality of care. Arch Intern Med 2010;170:1442-9.

28. Fitzmaurice GM, Laird NM, Ware JH. Applied longitudinal analysis. John Wiley \& Sons, 2012.

29. Gardiner JC, Luo Z, Roman LA. Fixed effects, random effects and GEE: what are the differences? Stat Med 2009;28:221-39.

30. Gunasekara FI, Richardson K, Carter K, et al. Fixed effects analysis of repeated measures data. Int J Epidemiol 2014;43:264-9.

31. Wiley Online Library. PRACTITIONERS' CORNER: Computing Robust Standard Errors for Within-groups Estimators ${ }^{\star}$ - Arellano - 1987 - Oxford Bulletin of Economics and Statistics. Available: https://onlinelibrary.wiley.com/doi/abs/10.1111/j.1468-0084.1987. mp49004006.x [Accessed 20 Nov 2018].

32. Williams R. Using the margins command to estimate and interpret adjusted predictions and marginal effects. Stata J 2012;12:308-31.

33. Deb P, Norton EC. Modeling health care expenditures and use. Annu Rev Public Health 2018;39:489-505.

34. Policy \& Medicine. Open payments data 2017: significant drop in number of payments. Available: https://www.policymed.com/2018/ 07/open-payments-data-2017-shows-significant-drop-in-number-ofpayments.html [Accessed 18 Jul 2019].

35. Chren MM, Landefeld CS. Physicians' behavior and their interactions with drug companies. A controlled study of physicians who requested additions to a hospital drug formulary. JAMA 1994:271:684-9.

36. Ruel E, Hauser RM. Explaining the gender wealth gap. Demography 2013;50:1155-76.

37. Meffert JJ. Key opinion leaders: where they come from and how that affects the drugs you prescribe. Dermatol Ther 2009;22:262-8.

38. Samuel AM, Webb ML, Lukasiewicz AM, et al. Orthopaedic surgeons receive the most industry payments to physicians but large disparities are seen in sunshine act data. Clin Orthop Relat Res 2015;473:3297-306.

39. Hockenberry JM, Weigel P, Auerbach A, et al. Financial payments by orthopedic device makers to orthopedic surgeons. Arch Intern Med 2011;171:1759-65.

40. de Lotbiniere-Bassett MP, McDonald PJ. Industry financial relationships in neurosurgery in 2015: analysis of the sunshine act open payments database. World Neurosurg 2018;114:e920-5.

41. Chamberlain JJ, Herman WH, Leal S, et al. Pharmacologic therapy for type 2 diabetes: synopsis of the 2017 American diabetes association standards of medical care in diabetes. Ann Intern Med 2017;166:572-8.

42. Liu JJ, Bell CM, Matelski JJ, et al. Payments by US pharmaceutical and medical device manufacturers to US medical Journal editors: retrospective observational study. BMJ 2017;359. 